\title{
On the relationship between cloud-radiation interaction, atmospheric stability and Atlantic tropical cyclones in a variable-resolution climate model
}

\author{
Louis-Philippe Caron • Colin G. Jones • \\ Paul A. Vaillancourt $\cdot$ Katja Winger
}

Received: 30 November 2011/Accepted: 4 February 2012/Published online: 24 February 2012

(C) The Author(s) 2012. This article is published with open access at Springerlink.com

\begin{abstract}
We compare two 28-year simulations performed with two versions of the Global Environmental Multiscale model run in variable-resolution mode. The two versions differ only by small differences in their radiation scheme. The most significant modification introduced is a reduction in the ice effective radius, which is observed to increase absorption of upwelling infrared radiation and increase temperature in the upper troposphere. The resulting change in vertical lapse rate is then observed to drive a resolution-dependent response of convection, which in turn modifies the zonal circulation and induces significant changes in simulated Atlantic tropical cyclone activity. The resulting change in vertical lapse rate and its implication in the context of anthropogenic climate change are discussed.
\end{abstract}

Keywords Tropical cyclones - Variable-resolution climate model - Radiation scheme - Atmospheric stability · Lapse rate $\cdot$ Convection $\cdot$ Cloud parametrization

\author{
L.-P. Caron ( $\square)$ \\ Department of Meteorology, Stockholm University, \\ Stockholm, Sweden \\ e-mail: caron@misu.su.se \\ L.-P. Caron \\ Bert Bolin Centre for Climate Research, Stockholm, Sweden \\ C. G. Jones \\ Rossby Centre, Swedish Meterological and Hydrological \\ Institute, Norrköping, Sweden \\ P. A. Vaillancourt \\ Numerical Weather Prediction Research Section, \\ Environment Canada, Dorval, QC, Canada \\ K. Winger \\ CRCMD Network, Université du Québec à Montréal, \\ Montreal, QC, Canada
}

\section{Introduction}

Global variable-resolution climate models offer an alternative to the more traditional nested approach used by regional climate models (RCMs) to produce dynamically downscaled climate simulations. With this technique, computing power is focused over a region of interest (through increased resolution), while resolution over the rest of the globe is relaxed toward lower values, more typical of global climate models (GCMs). Advantages of this approach include, but are not limited to, a coherent two-way interaction between the global and regional scales, as well as the elimination of a dependency upon a pilot simulation. Originally designed for numerical weather prediction, global variable-resolution models have made the transition to longer timescale use. Analysis has shown that, over the region of interest, simulations performed with variable resolution models compare advantageously to computationally equivalent (lower, fixed resolution) simulations and errors and biases are comparable to a simulation performed with uniform grid with resolution corresponding to the highest resolution of the variable grid (Fox-Rabinovitz et al. 2008).

The Global Environmental Multiscale (GEM) model is an atmosphere only model which can be integrated in different configurations, including the global, variableresolution configuration introduced above. In this mode, GEM is routinely used for a wide scope of applications, ranging from operational numerical weather prediction (Charron et al. 2011) to seasonal prediction (Markovic et al. 2011) and regional climate studies (Caron et al. 2011).

In June 2009, the top of the GEM model used for operational numerical weather prediction was raised from 10 to $0.1 \mathrm{hPa}$ and a new radiation scheme ( $\mathrm{Li}$ and Barker 
2005) was implemented (Charron et al. 2011). Initial tests with this new radiation scheme showed significant improvements to long existing problems while also introducing some minor biases. The latter were corrected with several modifications related to the cloud-radiation interaction. It was later realized in the context of two independent projects studying TC activity in NWP mode (Zadra et al. 2012) and climate mode (Caron et al. 2011) that these modifications led to a significant reduction (improvement) in TC activity. Based on two 28-year simulations made with and without these modifications, we explore the link between the radiation changes and simulated TC activity.

In Sect. 2, we introduce the atmospheric model used in this study while in Sect. 3 we discuss the radiative changes implemented in the newer version of GEM as well as their impact on atmospheric stability. In Sect. 4, we discuss the impact of the changes on tropical cyclone statistics, such as number and intensity, and on large-scale fields known to impact cyclogenesis, while in Sect. 5 we discuss the role played by resolution in the observed changes. We end with some concluding remarks in Sect. 6.

\section{Model description and configuration}

Global Environmental Multiscale is fully non-hydrostatic, employing a semi-implicit, semi-Lagrangian dynamical core on an Arakawa staggered C-grid. The model uses a hybrid terrain following vertical coordinate (Laprise 1992). Unless otherwise stated, the results discussed in this paper were obtained in variable resolution (referred to as GVAR) mode with 60 vertical levels (top at $2 \mathrm{hPa}$ ). GEM uses the Kain-Fritsch scheme (Kain and Fritsch 1990) for deep convective processes, the Kuo transient scheme for shallow convection (Kuo 1965; Bélair et al. 2005), the Sundqvist scheme (Sundqvist et al. 1989) for large-scale condensation and a correlated-K scheme for longwave and part of the shortwave radiation ( $\mathrm{Li}$ and Barker 2005). Subgridscale orographic gravity wave drag is due to McFarlane (1987) and low-level orographic blocking to Zadra et al. (2003). Land surface processes are represented by the ISBA scheme (Bélair et al. 2003). Finally, sub-grid scale turbulent fluxes are calculated using an implicit vertical diffusion scheme with prognostic turbulent kinetic energy and a mixing length based on Bougeault and Lacarrère (1989), Bélair et al. (1999). The interested reader is referred to Zadra et al. (2008) and Côté et al. (1998) for more details.

Two integrations were made, with and without the modifications to cloud and radiation parameterizations, which are described in the next section. Both integrations were performed using a global variable resolution (GVAR)

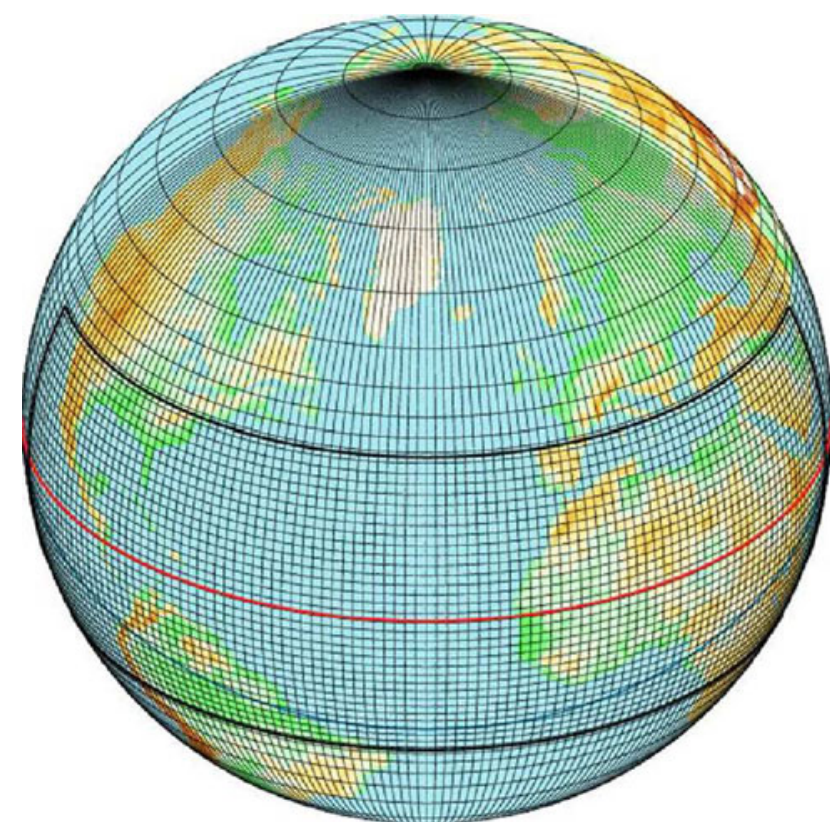

Fig. 1 Global variable grid used in this study. The thick black line separates the high-resolution area from the increasingly low resolution area. The red line is the grid equator, while the blue line is the true equator

grid, where the area of high resolution $\left(0.3^{\circ}\right)$ extends from the Eastern Pacific to the Arabian Sea and between $5^{\circ} \mathrm{S}$ and $45^{\circ} \mathrm{N}$ while the remaining part of the Globe is progressively relaxed to $2^{\circ}$ resolution (Fig. 1). The integrations have been performed using observed SSTs and sea-ice fraction derived from the Atmospheric Model Intercomparison Project v2 (AMIP2; Gleckler 1996), applied in the model on a daily basis from linearly interpolated monthly mean data. Both were integrated starting on September 1st, 1978, and ending on December 1st, 2006.

\section{Radiative adjustments}

The two 28-year integrations are performed using similar versions (3.2.2 and 3.3.0) of the GEM model. Slight modifications were applied to GEM 322 (which then became GEM 330) with the goal of correcting a cold bias in the vertical temperature profile of the tropics found relative to radiosonde observations and to ERA40 reanalyses. Four modifications were introduced in the new version 330 in order to address this bias. Three of these are related to cloud and radiation processes, the most significant of which was a change to the effective radius of ice clouds. A short description of the modifications is given below.

1. The ice effective radius was reduced from a variable $20-50 \mu \mathrm{m}$ to a constant value of $15 \mu \mathrm{m}$. This decrease 
in ice effective radius leads to an increase in the reflectivity/absorptivity and emissivity of high ice clouds. In the shortwave, this causes a slight increase in heating rates in the cirrus region and a decrease in shortwave heating below these clouds. In the longwave, there is a decrease in cooling rate for the whole troposphere due to increased longwave absorption by high cirrus. This last effect dominates, leading to an increase in temperature for most of the troposphere, with maximum increase at $250 \mathrm{hPa}$.

2. An upper limit to cloud condensate passed on to the radiation scheme was removed. In GEM 322, a maximum corresponding to $50 \%$ of the total cloud condensate of a saturated parcel leaving the surface and following a moist-adiabat was imposed as being radiatively active (Betts and Harshvardan 1987). This change leads to an increase in radiatively active liquid and solid condensate, leading to a slight decrease in longwave cooling rate as well as an increase in shortwave heating rate. The net effect is a modest increase in heating rate, which results in a small temperature increase throughout the troposphere, with a peak near $100 \mathrm{hPa}$.

3. The parameterization for partitioning total condensate into liquid and solid fractions was modified from Rockel et al. (1991) in GEM 322 to that due to Boudala et al. (2007) in GEM 330. The new condensate distribution results in a modest decrease in the longwave cooling rate below cloud level, which in turn leads to a small temperature increase over the majority of the troposphere.

4. Finally, the $2 \mathrm{~m}$ air temperature was used instead of the ground skin temperature at the first flux level for longwave calculations. This modification has an impact on the longwave cooling rates in the first model levels near the surface, with a slight warming in the boundary layer, but no significant impact on boundary layer fluxes or convective activity.

\subsection{Impact on vertical stability}

We begin by examining the impact of these changes on simulated OLR. Figure 2 shows the mean ERA40 OLR and differences in mean OLR between the two GVAR integrations and ERA40 reanalysis for the period ASO 1979-2002. ${ }^{1}$ Significant improvements are visible throughout the tropics in GEM 330, mainly through widespread reduction of a strong positive OLR bias present in GEM 322. This is particularly true over areas dominated by deep convection and upper tropospheric cirrus clouds, such as the West and

\footnotetext{
${ }_{1}^{1}$ We limited the comparison period to the period covered by ERA40 reanalysis.
}

equatorial Pacific and the Indian Ocean, where a positive OLR bias of $\sim+30-40 \mathrm{~W} \mathrm{~m}^{-2}$ is reduced to $\sim+10-15$ $\mathrm{W} \mathrm{m}^{-2}$. Such a reduction is consistent with higher emissivity (more opaque) upper tropical troposphere (UTT) clouds.

We also examine the impact of these modifications on atmospheric heating and temperature profiles simulated by both versions of GEM. Ideally, we would perform this comparison using the high-resolution 28-year integrations, but some of the necessary variables and levels are missing in these model output. Instead, we contrast the results obtained in the context of 4-year long climate runs (1998-2001) performed with two uniform resolution global versions of GEM (322 and 330) run at $0.9^{\circ}$. Good agreement is found when comparing the available temperature levels between the GVAR and the lower $0.9^{\circ}$ resolution (not shown). Figure $3 \mathrm{a}-\mathrm{c}$ shows the mean vertical profile of ASO heating rate due to longwave, shortwave and total radiation for both GEM 322 and GEM 330 over the main development region (MDR) for Atlantic tropical cyclones (defined here as $8^{\circ} \mathrm{N}, 20^{\circ} \mathrm{N}, 80^{\circ} \mathrm{W}$ and $20^{\circ} \mathrm{W}$ ). Figure $3 \mathrm{a}$ shows an increase (decrease) of the heating rate driven by shortwave radiation in the upper (mid-) troposphere in GEM 330 compared to GEM 322. An accompanying decrease in longwave cooling rates are observed in GEM 330 in the mid- to upper troposphere and near the surface (Fig. 3b). Similar changes in heating rates and temperature profiles are also seen for other convectively active regions of the tropics.

Figure $3 d$ shows the resulting change in the vertical temperature profile over the MDR. In moving from GEM 322 to 330 , there is a $\sim 1.5^{\circ} \mathrm{C}$ increase in upper tropospheric temperatures and a more modest $\left(\sim 0.6^{\circ} \mathrm{C}\right)$ increase in the mid- to lower troposphere. The primary cause of this warming is the reduced ice effective radius, leading to reduced IR cooling below frequent UTT clouds. The impact of this is enhanced by the two modifications that increase the radiatively active ice condensate, leading to changes in upper-level reflectivity/absorptivity and emissivity. The net effect on temperature over the MDR, and the tropics in general, is also seen in global mean temperature profiles although with reduced amplitude, due to the more frequent occurence of very high cirrus in the tropics than the global average. Finally, we detect a reduced effect in the mid-troposphere (near $500 \mathrm{hPa}$ ) where there are very few clouds in the model tropics.

The difference between the two vertical temperature profiles (Fig. 3d) shows that cloud and radiation changes lead to a vertical stabilization of the atmosphere due to a stronger $\left(1.5^{\circ} \mathrm{C}\right.$ compared to $\left.0.6^{\circ} \mathrm{C}\right)$ warming in the upper troposphere compared to the lower layers of the atmosphere. Vertical stabilization of the atmosphere generally reduces the frequency of deep precipitating convection. 
Fig. 2 Mean ERA40 OLR (a) and mean OLR differences between GVAR 322 and GVAR 330 (322-330) (b), GVAR 322 and ERA40 (322-ERA40)

(c) and GVAR 330 and ERA40

(330-ERA40) (d) for the ASO

1979-2002 period. Units are $\mathrm{W} \mathrm{s}^{-2}$
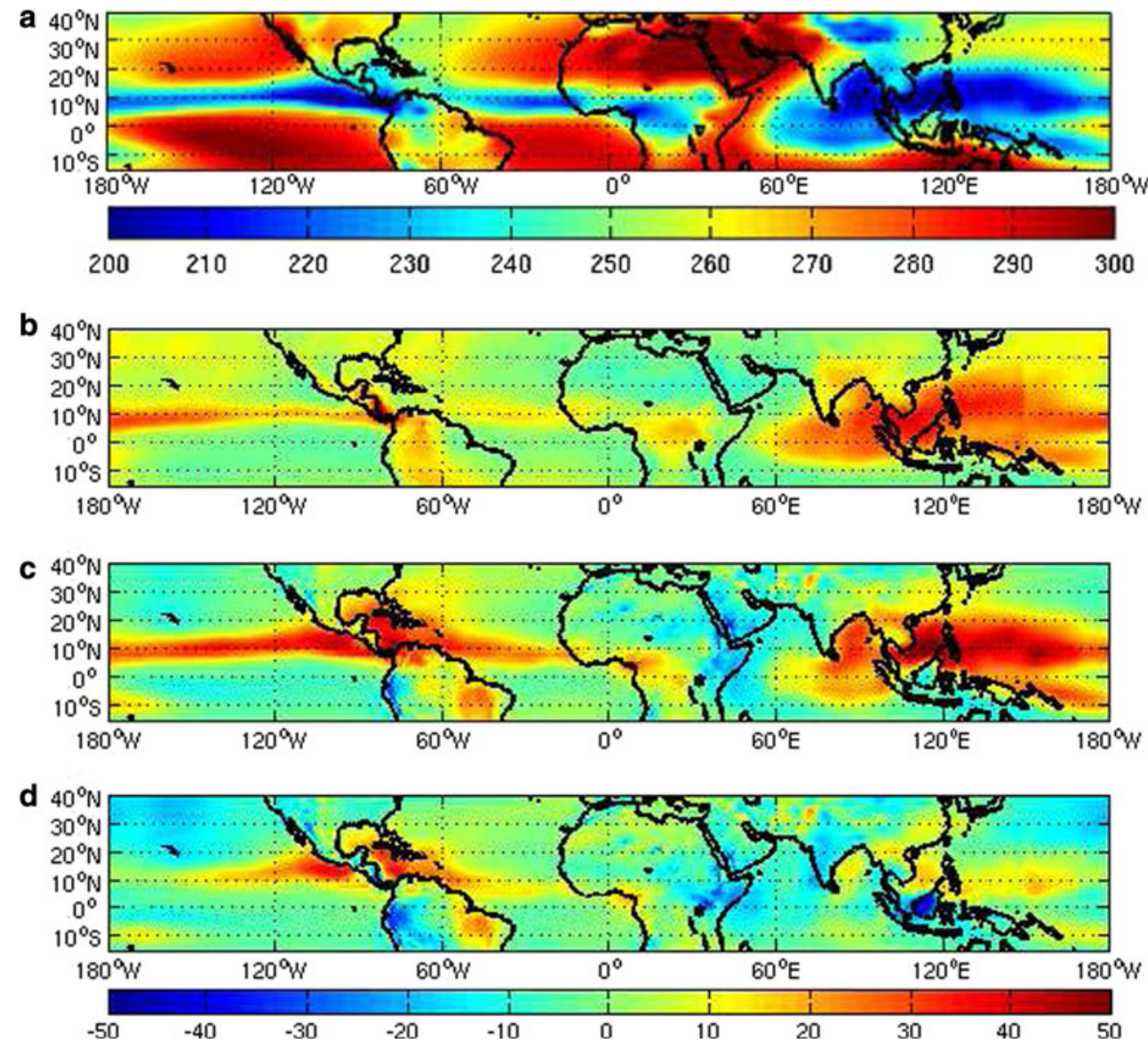

Fig. 3 Mean ASO vertical heating rate profiles in GEM 322 and GEM 330 and differences therein due to a shortwave radiation, b longwave radiation and $\mathbf{c}$ total radiation over the main development region. The resulting difference in the vertical temperature profile as well as the differences with respect to ERA40 are shown in $\mathbf{d}$ a
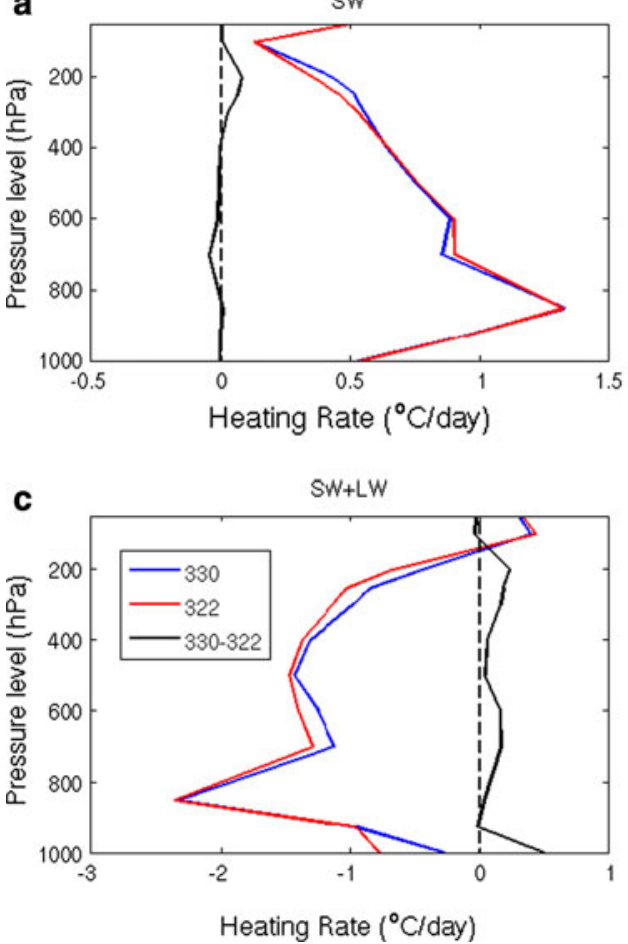

b

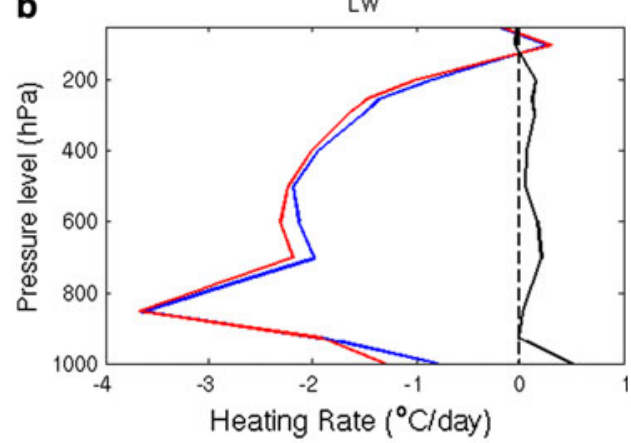

d Difference in Temperature Profile

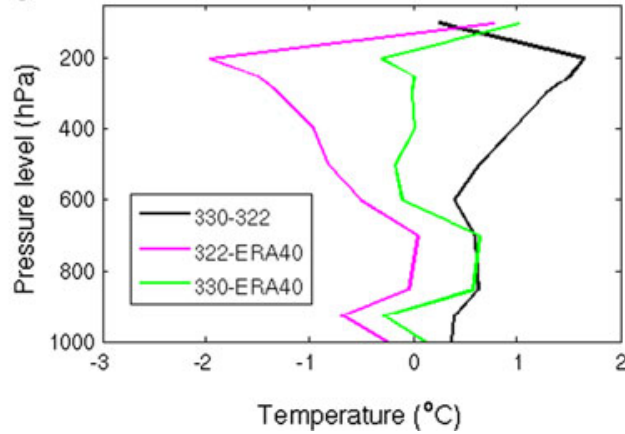


Stability of the atmosphere/ocean system is a component of the Seasonal Genesis Parameter (Gray 1975) and Genesis Potential Index (Emanuel and Nolan 2004) that relate large-scale fields to TC activity. One would therefore expect a change in static stability to impact simulated TC activity. This will be investigated in the following section.

\section{Atlantic tropical cyclone activity}

\subsection{Detection and tracking}

In order to compare simulated and observed TC activity, we detect and track simulated TCs through an automated procedure. This procedure is only briefly described here, a more detailed discussion can be found in Caron et al. (2011). To determine if a TC is present, the procedure searches the simulations for a combination of atmospheric conditions, similar to those observed in "real" TCs. When the objective criteria are satisfied for a sufficient number of consecutive timesteps, a TC is considered to be present. The criteria used to detect TCs, derived from Walsh et al. (2007), are as follows:

- a minimum in central pressure $<1,013 \mathrm{hPa}$.

- a relative vorticity maximum at $850 \mathrm{hPa}>4 \times 10^{-5} \mathrm{~s}^{-1}$.

- the surface $(10 \mathrm{~m})$ winds exceed $17 \mathrm{~m} \mathrm{~s}^{-1}\left(65 \mathrm{~km} \mathrm{~h}^{-1}\right)$ in the vicinity $\left(<2^{\circ}\right.$ of the center).

- the number of consecutive, detected centers cover at least a $24 \mathrm{~h}$ period.

- a positive temperature anomaly exists in the mid- to upper-troposphere. This warm core anomaly is detected if the maximum (spatially-mean) temperature, in the vicinity $\left(<2^{\circ}\right)$ of the center at 500 and $250 \mathrm{hPa}$, is $>1$ and $>0^{\circ} \mathrm{C}$, respectively, higher than the mean temperature at a radius of $<5^{\circ}$ for the same two pressure levels.

- the low-level $(850 \mathrm{hPa})$ vorticity is higher than the upper-level (250 hPa) vorticity.

For comparison, observed TC tracks are taken from the National Hurricane Center best track database (HURDAT). ${ }^{2}$

\subsection{Cyclogenesis}

Figure 4 shows all cyclogenesis events for observations, GEM 322 and GEM 330 during the JJASON 1979-2006 period while Fig. 5 shows the corresponding storm tracks. The observed distribution of cyclogenesis is relatively well reproduced by both simulations, with a large number of

\footnotetext{
${ }^{2}$ Available online at http://www.nhc.noaa.gov/pastall.shtml.
}

storms originating from easterly waves off the African coast in what is referred to as the main development region. Model storms also form east of the American coast in numbers relatively similar to observations. A low number of TCs in the Gulf of Mexico and Caribbean Sea in both model versions was linked to the combined effect of a dry bias in the atmosphere and high vertical wind shear in these regions (Caron et al. 2011).

Comparison of Fig. 4b, c shows a quite significant reduction in the number of TCs, from a total of 423 in GEM 322 to 282 in GEM 330. GEM 330 shows an overall reduction of $33 \%$ in TCs compared to GEM 322, and an almost $40 \%$ reduction when only the MDR is considered, bringing the total storm occurrence from 109 above (average of $+3.9 \mathrm{TCs} / \mathrm{year}$ ) to 32 below the observed number (average of $-1.1 \mathrm{TCs} / \mathrm{year}$ ). This reduction in TC numbers is apparent across all years.
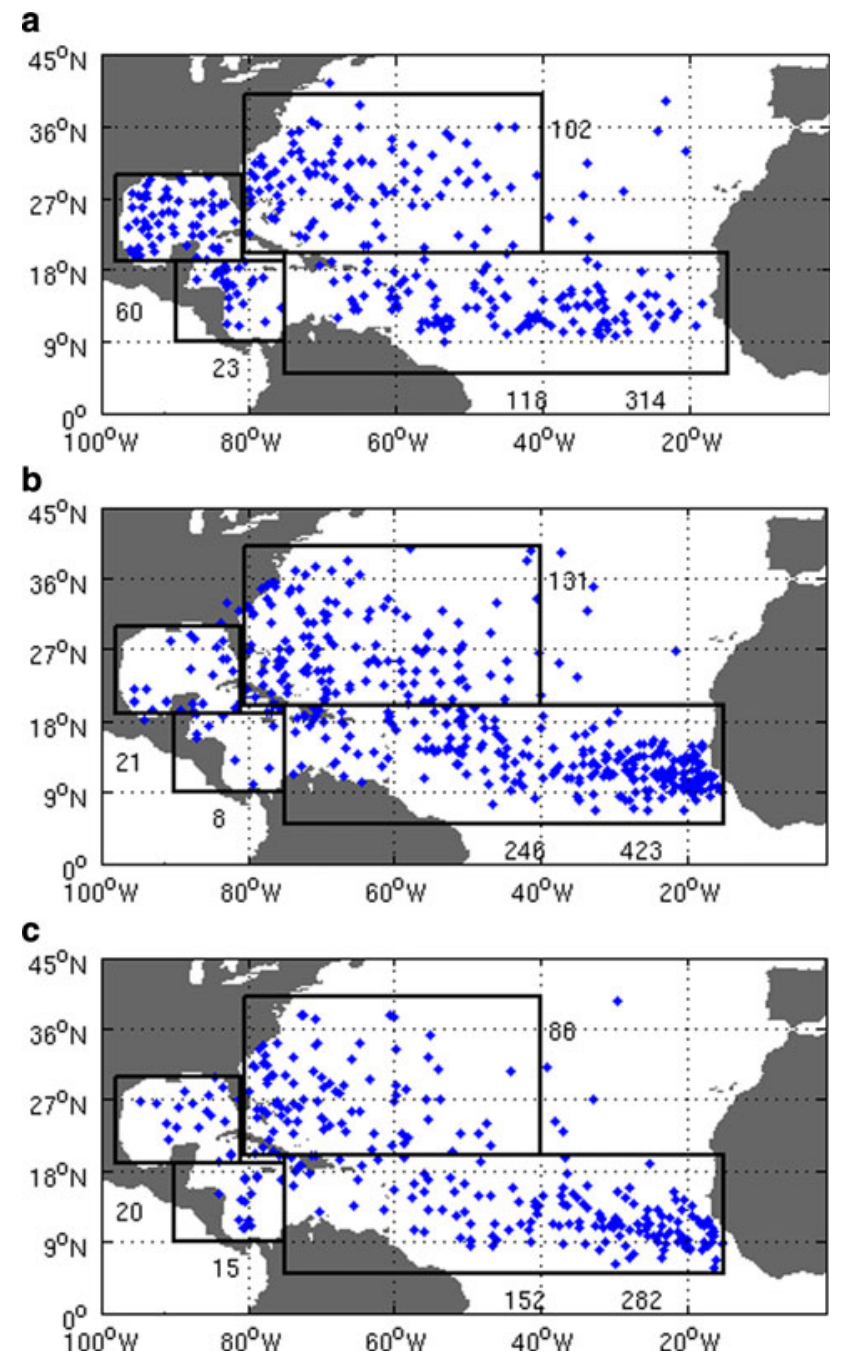

Fig. 4 Cyclogenesis locations for a observations (National Hurricane Center database), b GEM 322 and c GEM 330 during the JJASON 1979-2006 period 

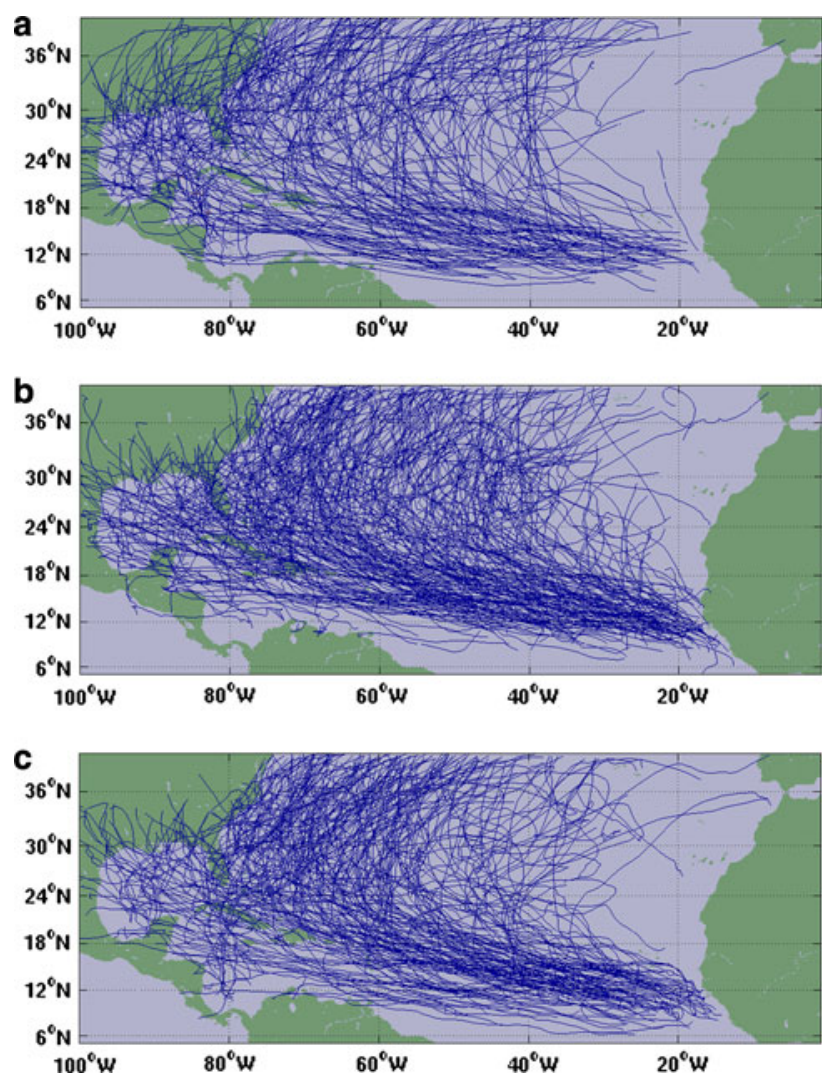

Fig. 5 JJASON 1979-2006 tracks for a observations, b GVAR 322 and $\mathbf{c}$ GVAR 330

The reduction in TC activity in GEM 330 is consistent with the change in the vertical temperature profile resulting from the radiation changes discussed in Sect. 3 that act to stabilize the atmosphere. All other things being equal, an increase in vertical stability should lead to a reduction of TC numbers. However, to gain a more complete understanding of the cause of the TC reduction discussed above, we first examine other relevant large-scale fields.

\subsection{Large-scale fields}

Besides atmospheric stability, other factors impacting cyclogenesis include (Gray 1975):

- sea surface temperature

- mid-tropospheric humidity

- low-level vorticity

- vertical wind shear

Comparison of the respective fields shows that only the mean ASO vertical wind shear varies significantly between the two versions, with GEM 330 displaying higher vertical wind shear than GEM 322 in a large swathe across the tropical Atlantic (Fig. 6a). The detrimental influence of high vertical wind shear on TCs is usually understood to arise through ventilation of a developing warm core in the upper troposphere, which leads to a rise in central surface pressure and a weakening of the storm. Significant differences ( $>40 \%$ of the absolute wind shear values) are observed over a large portion of the MDR.

Figure 7 shows a scatter plot of the total number of TCs forming in the MDR with respect to the mean ASO MDR wind shear for an ensemble of simulations performed with GEM 330 in limited-area mode (LAM; in black) as shown in Caron and Jones (2011). Here, we have also added the data for GVAR 322 (in red) and GVAR 330 (in green). Both GVAR simulations produce a total number of storms which fall close to the best-fit obtained from the GEM 330 LAM simulations. Thus, the level of TC activity in GVAR 322 , despite a more unstable atmosphere, is more or less what we would expect in GEM 330 given the level of vertical wind shear in 322. In other words, the direct impact of stability differences appears to be secondary to differences in vertical wind shear, which must themselves come about as a consequence of the radiative changes.

To understand the origin of the changes in vertical wind shear, we start by showing the differences in upper ( 250 $\mathrm{hPa})$ and lower $(850 \mathrm{hPa})$ zonal and meridional winds between GVAR 322 and GVAR 330 in Fig. 8. Most of the increase in vertical wind shear over the MDR in GEM 330 occurs through changes in the zonal components at 250 and $850 \mathrm{hPa}$ : GVAR 330 simulates both stronger trade

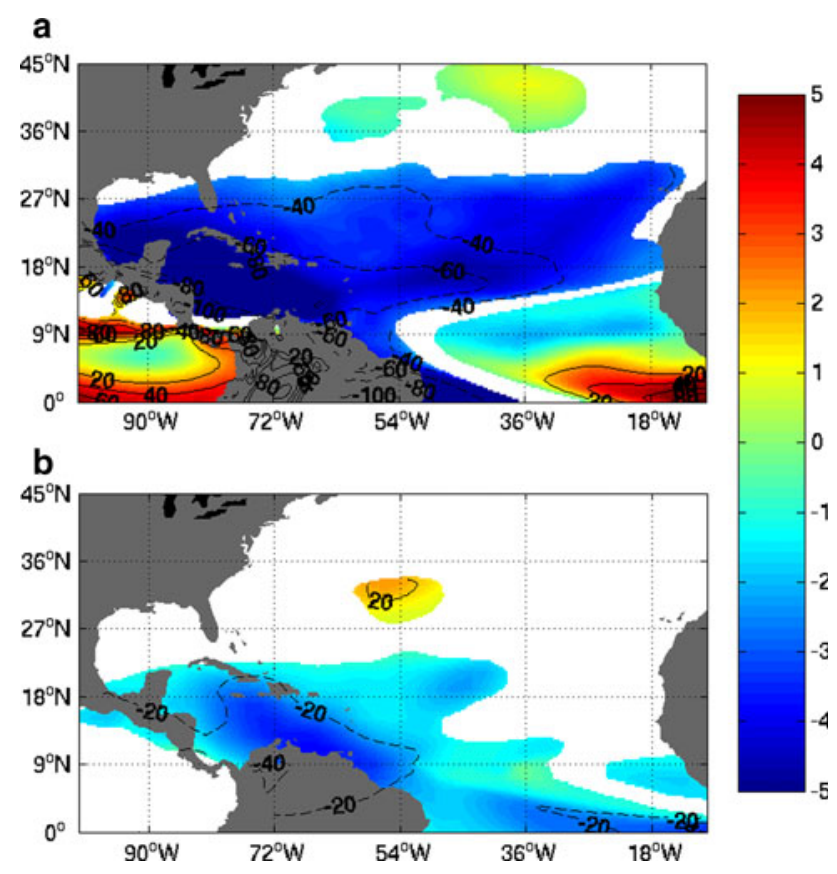

Fig. 6 Mean ASO vertical wind shear differences between a GVAR 322 and GVAR 330 and b Global $2^{\circ} 330$ and Global $2^{\circ} 322$ (322-330). Units are $\mathrm{m} / \mathrm{s}$. Only differences significant at the $95 \%$ level on based on Student's $t$ test are shown. The full/dashed lines represent the positive/negative relative differences with respect to the mean seasonal wind shear values [(GEM $330+$ GEM 322)/2] 
Fig. 7 Relationship between mean ASO MDR vertical wind shear and total number of TCs forming in the MDR. Red is GVAR 322, green is GVAR 330 and in black are a range of LAM simulations performed with GEM

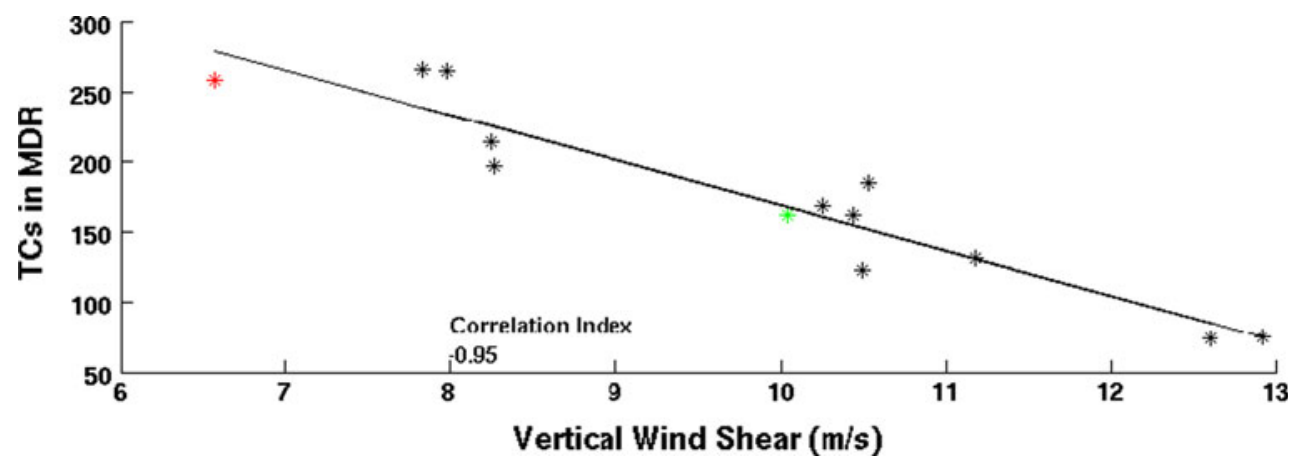

winds and stronger upper-level westerlies compared to GVAR 322.

Figure 9a shows the mean (ASO) difference in vertical velocity at $700 \mathrm{hPa}$ (a good proxy for convection) between GVAR 330 and 322 over the Northern Atlantic and part of the Pacific. A strong decrease in convective activity in GVAR 330 can be seen, both in the eastern Atlantic, just off the African coast and in the tropical East Pacific. Goldenberg and Shapiro (1996) show that increased convective activity over Africa can lead to reduced shear over the Atlantic MDR region. This occurs through the combined effects of reduced lower tropospheric easterly trade winds and reduced upper-level westerlies. As a consequence we would expect an increase in wind shear over the MDR in GVAR 330 compared to 322.

Figure $10 \mathrm{a}, \mathrm{b}$ shows the correlation between the difference (GVAR322-GVAR330) in mean ASO vertical velocity $(\omega)$ at $700 \mathrm{hPa}$ over the area where these differences are the largest $\left(30^{\circ} \mathrm{W}, 10^{\circ} \mathrm{W}, 14^{\circ} \mathrm{N}, 8^{\circ} \mathrm{N}\right)$ and the mean differences in ASO 250/850 hPa zonal winds. Areas of significant correlation in Fig. 10a, b coincide closely with the regions of maximum difference in 250 and 850 $\mathrm{hPa}$ zonal winds shown in Fig. 8, suggesting stronger convection off the west African coast in GVAR322 leads to lower vertical wind shear over the MDR, with this likely being the main cause of higher TC numbers in the GVAR322 simulation.

Stronger convective activity in the eastern Pacific in GEM 322 compared to GEM 330 also likely contributes to the increase in Atlantic TC activity. Increased convective activity over this region is associated with upper-level easterly anomalies over large portions of the tropics, which act to reduce the mean (westerly) upper-level flow (not shown), thereby also contributing to a reduction in tropical Atlantic wind shear. This is supported by significant correlation values (significant at the $95 \%$ level significance) between mean seasonal eastern Pacific convection (measured by $\omega$ at $700 \mathrm{hPa}$ ) and $250 \mathrm{hPa}$ zonal winds over large portion of the tropical North Atlantic (not shown).

Finally, Fig. 4 shows that GVAR 330 also produces fewer TCs over the subtropics $\left(20^{\circ} \mathrm{N}-40^{\circ} \mathrm{N}, 40^{\circ} \mathrm{W}-80^{\circ} \mathrm{W}\right)$ compared to GVAR 322. Changes in vertical wind shear between the two integrations over this region are negligible and therefore not likely responsible for the detected difference. The impact of the radiative changes over this region (not shown) is somewhat reduced compared to the
Fig. 8 Mean ASO differences between GVAR 322 and GVAR 330 a $250 \mathrm{hPa}$ zonal wind, b $250 \mathrm{hPa}$ meridional wind, c $850 \mathrm{hPa}$ zonal wind and d 850 $\mathrm{hPa}$ meridional wind. Differences are GVAR 322GVAR 330 and units are m/s. Only values significant at the 95\% level (based on Student's $t$ test) are shown. The lines represent the relative differences with respect to the mean seasonal values [(GVAR $330+$ GVAR 322)/2]
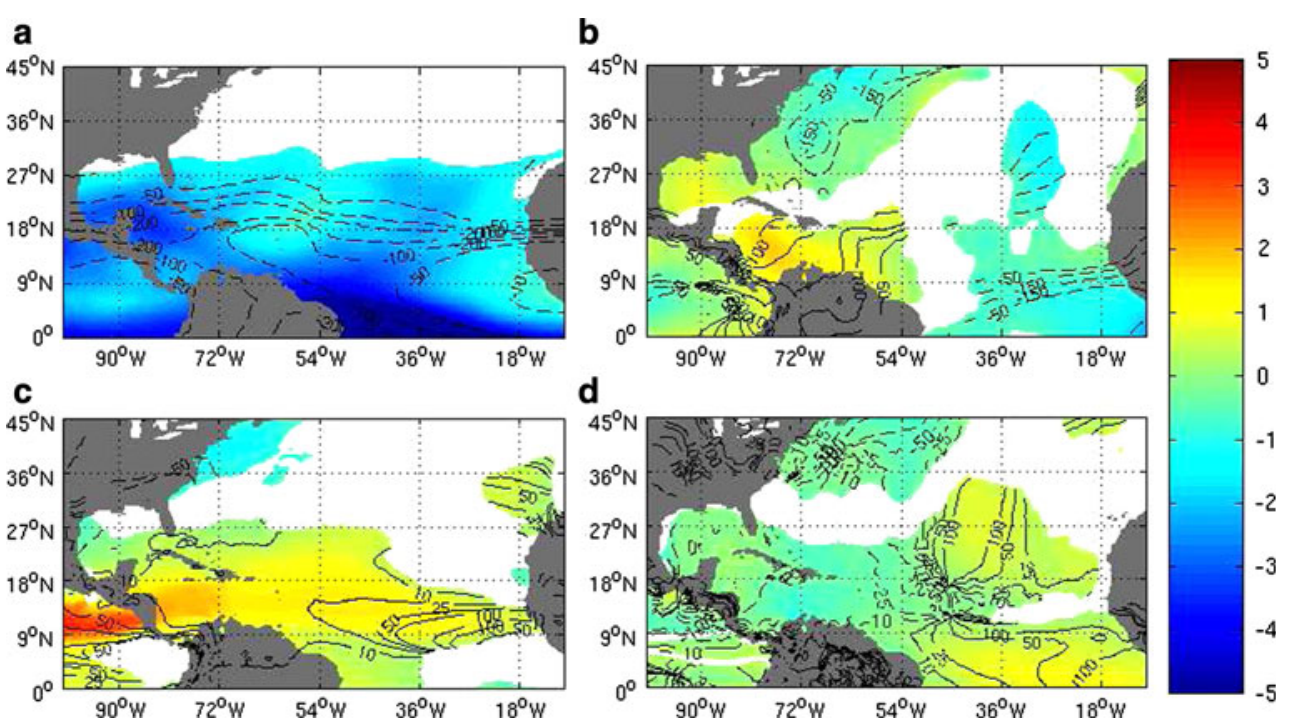


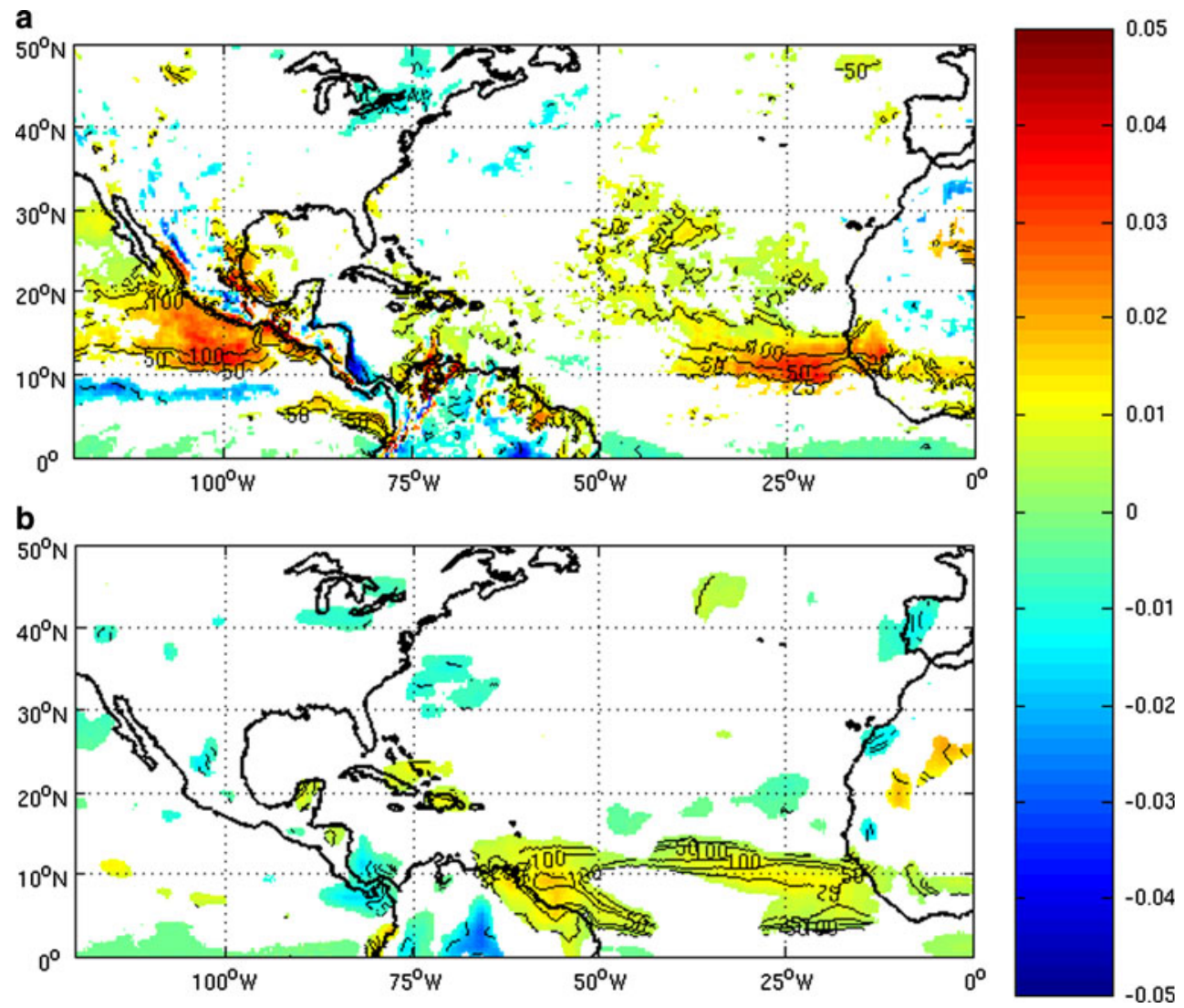

Fig. 9 Mean ASO differences in $700 \mathrm{hPa}$ vertical velocity between a GVAR 330 and GVAR 322 and b Global 330 and Global 322 (330-322). Only values significant at the 95\% level (based on Student's $t$ test) are shown. Units are $\mathrm{Pa} / \mathrm{s}$. The full/dashed lines

MDR (Fig. 3d) due to the formation of fewer upper-level clouds: a mean (ASO) increase of $\sim 0.7^{\circ}\left(\sim 0.2^{\circ}\right)$ is apparent at the $250(850) \mathrm{hPa}$ level in GVAR 330 compared to GVAR 322. Everything remaining equal, this change in temperature profile would still tend to increase stability and reduce TC activity in GEM 330. However, the decrease in number of storms could also be caused by a decrease in the number of AEWs surviving the trip across the MDR (or being weaker) due to less favorable conditions in GEM 330.

In order to determine the dominant influence, we reran the tracking routine to track tropical waves with maximum wind speeds greater than $7.5 \mathrm{~m} / \mathrm{s}$ (in essence, we lowered the wind speed threshold). This, of course, significantly increases the number of systems detected in the simulations. We then counted the number of systems that were below TC strength when crossing from the MDR into the region north of $25^{\circ} \mathrm{N}$ between and $40^{\circ} \mathrm{W}$. The mean intensity of these waves was almost equal in both simulations, however GVAR 330 had only $64 \%$ of the total number of waves in GVAR 322. This ratio is relatively similar to the ratio of $67 \%$ in cyclogenesis formation represent the positive/negative relative differences with respect to the mean [(GVAR $330+$ GVAR 322)/2] seasonal values. Blue means more ascending motion in 330, red/yellow, more ascending motion in 322

detected over the subtropical region, suggesting the reduced number of incoming waves reaching a certain intensity threshold is likely the predominant factor for TC reduction over that part of the basin.

\subsection{Intensity}

Figure 11 shows the relative TC maximum intensity distribution for storms forming in the MDR for both GEM 322 and GEM 330. Maximum in storm intensities are compared using the minimum in surface pressure as opposed to maximum in surface wind speed since the latter is underestimated in GEM TCs (see Caron and Jones 2011 for more discussion), while the simulated central surface pressures cover a more representative distribution of observed intensities.

Figure 11 shows a significant difference in the storm intensity distribution between the two integrations: GEM 322 produces more intense storms than GEM 330, as well as producing the intense $(<960 \mathrm{hPa})$ storms more frequently. Based on the Kolmogorov-Smirnov significance test, the two distributions differ at the $95 \%$ confidence level. In absolute number, GEM 322 produces 42 storms 
Fig. 10 Temporal correlations between mean ASO vertical velocity differences within the rectangular area and mean seasonal differences in zonal winds at individual grid points at a $250 \mathrm{hPa}$ and $\mathbf{b} 850 \mathrm{hPa}$. Differences are between GVAR 322 and GVAR 330. Only correlations significant at the 95\% level are shown

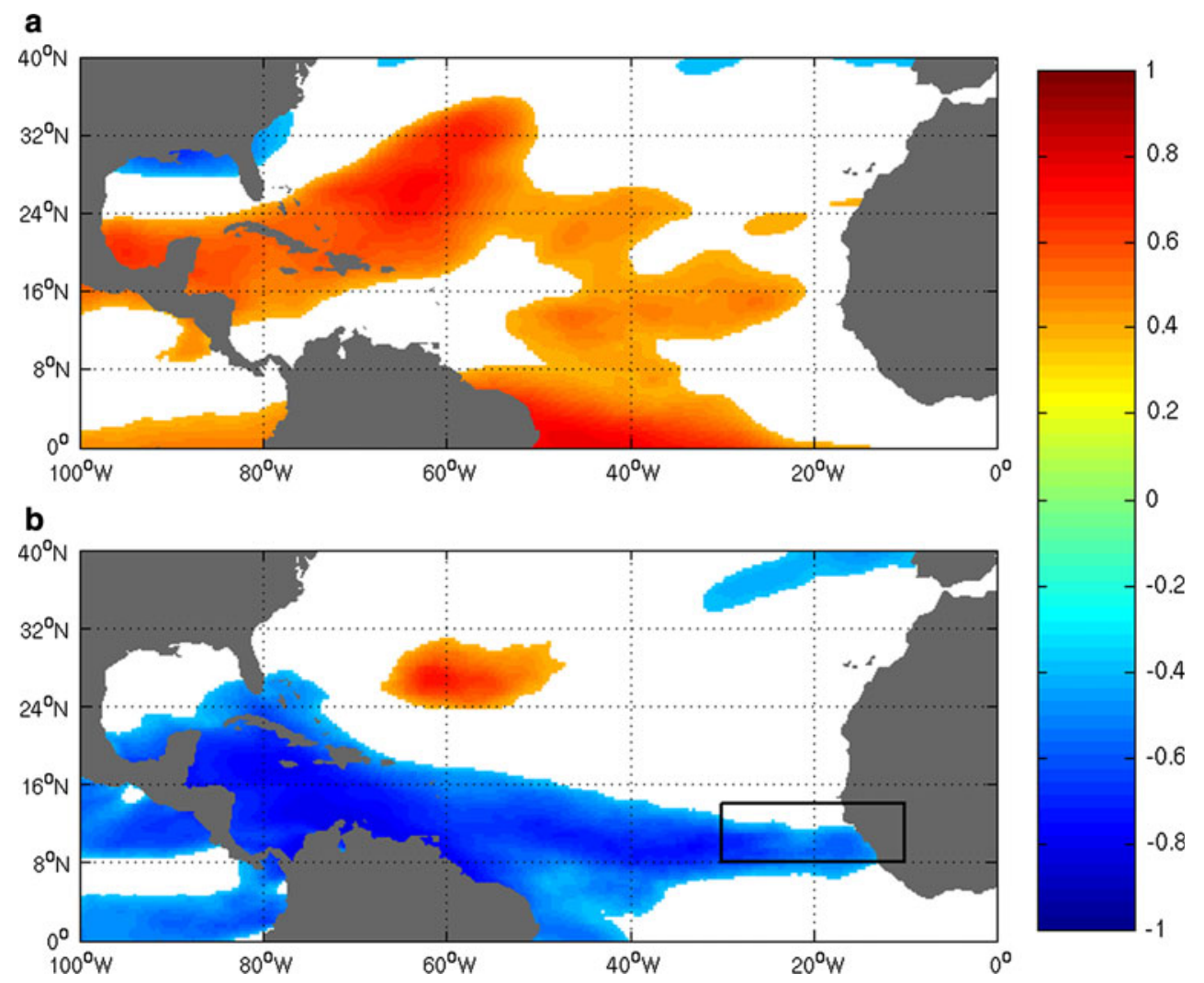

Fig. 11 Relative distribution of maximum storm intensity (based on minimum surface pressure) for TCs forming in the MDR in GVAR 322 and GVAR 330

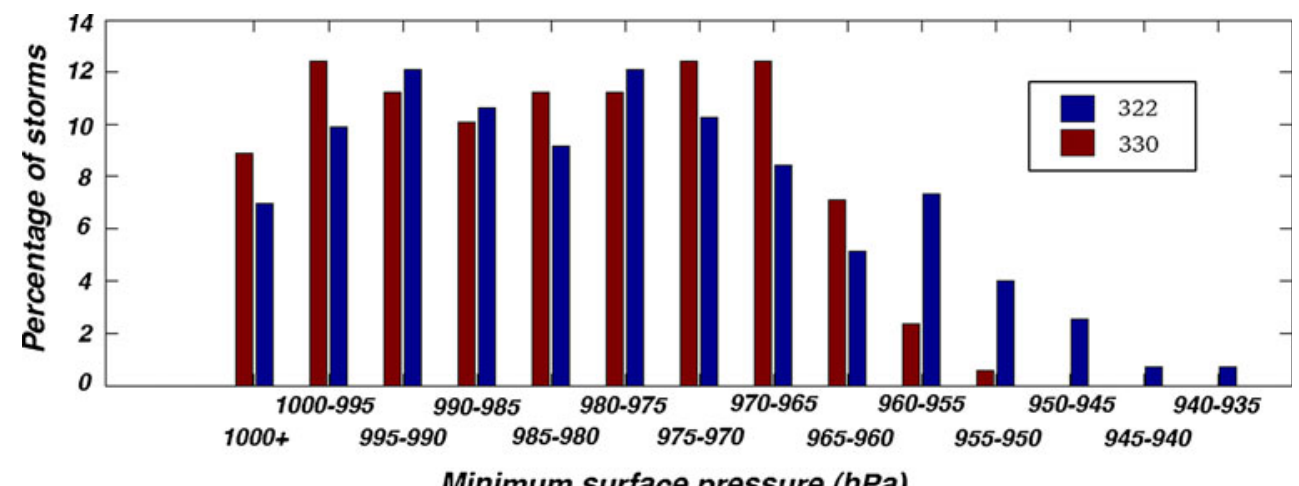

Minimum surface pressure ( $\mathrm{hPa}$ )

with minimum surface pressure below $960 \mathrm{hPa}$ while GEM 330 produces only 5 . The minimum surface pressure reached by a storm in GEM 322 is $937 \mathrm{hPa}$ (category 4) while in GEM 330 it reaches $951 \mathrm{hPa}$ (category 3). This decrease in the intensity of the most intense storms in GEM 330 is somewhat expected since the intensity of a mature cyclone is found to be "highly correlated with the energy available from moist-adiabatic ascent in the eyewall relative to a reference sounding in the undisturbed environment" (Shen et al. 2000). Thus, in GEM322, the excess instability skews the intensity distribution towards more intense storms which, combined with the effect of fixed SSTs, results in the presence of storms much stronger than that typically expected for $\sim 30 \mathrm{~km}$ resolution simulations.
Finally, storms in the early stages of their development (minimum surface pressure $>1,005 \mathrm{hPa}$ ) in GEM 322 tend to intensify faster than storms in GEM 330 (not shown) at a similar stage. This is likely due to the extra CAPE available to intensify the storm in GEM 322. However, this effect appears to dissipate quickly $(\sim 6 \mathrm{~h})$.

\section{Discussion}

Two additional simulations were also performed with both versions of the model. These simulations covered the same period (1979-2006), but were performed at a fixed $2^{\circ}$ resolution. The impact of radiative changes on convection 
are significantly different in GVAR (Fig. 9a) compared to the fixed $2^{\circ}$ simulations (Fig. 9b): none of the strong differences (in an absolute sense) visible in the eastern Atlantic and eastern Pacific in GVAR are present in these lower resolution simulations. The small absolute differences that can be seen over part of the southern North Atlantic in the lower resolution simulations are, in a relative sense, comparable to the (relative) differences observed in the GVAR simulations and indicate that the vertical velocities (and convection) at higher resolution are stronger than in low resolution simulations. ${ }^{3}$ Not surprisingly, the respective response of the tropical atmospheric circulation to these changes also differs significantly between the two sets of integrations.

The impact of this resolution-dependent response can readily be seen in Fig. 6: the lower resolution GEM330GEM322 simulations show much smaller differences (although they do show the same tendency) in vertical wind shear over the tropical Atlantic (Fig. 6b) compared to their GVAR counterparts (Fig. 6a), likely due to the weaker convective response off Africa in the $2^{\circ}$ run and how it projects onto the tropical circulation. Any attempts at evaluating the TC response through the use of cyclogenesis indices (which include the influence of vertical shear), as is routinely done for lower resolution GCMs, would likely yield significantly smaller differences in TC numbers in the $2^{\circ}$ GEM simulations compared to the GVAR runs.

This difference in the response between the two configurations we suggest occurs due to a resolution-dependent interaction between parameterized moist convection and resolved scale dynamics. Williamson and Boville (1998) discussed the sensitivity of the CCM2 GCM to model resolution. He noted a clear tendency for a more intense and deeper thermally driven vertical circulation as model resolution increased over the range T42 to T170 spectral truncation, with no convergence of the solution up to T170. He further found that if the physical parameterizations in $\mathrm{CCM} 2$ were constrained to run (i.e. provide forcing tendencies to the resolved dynamics) on a fixed resolution grid of T42, while the resolved dynamics were calculated on an increasingly finer grid, then convergence of the thermallydirect Hadley circulation was seen, with the solution across all dynamic resolutions, resembling that of the full model (physics and dynamics both on the same full-resolution grid) at a resolution supported by the parameterization grid. The conclusion being that parameterized forcing, representing scales smaller than the resolved dynamics, interacts with dynamics in such a way that a localized region of

\footnotetext{
${ }^{3}$ Convection $(\omega$ at $700 \mathrm{hPa}$ ) and wind shear anomalies in the two 4-year simulations performed at $0.9^{\circ}$ resolution (used to derived vertical profiles in Sect. 3.1) seem to lie somewhere between those of fixed $2^{\circ}$ and GVAR simulations.
}

increased sub-grid scale forcing (heating) is amplified relative to the surroundings, through diabatic (convective) heating inducing a low-level convergent flow into the area of convection and that this amplification increases local to the diabatic heating maximum as model resolution increases.

Jung and Arakawa (2004) also emphasized the strong resolution sensitivity of sub-grid scale forcing, primarily moist convection, in experiments with a 2-dimensional non-hydrostatic model. The mechanism behind such amplification is analogous to the CISK (Conditional Instability of the Second Kind) feedback, first proposed by Charney and Eliassen (1964) and Ooyama (1964) as the main mechanism behind tropical cyclone development. In CISK a small region of the atmosphere, initially experiencing diabatic heating larger than the surrounding atmosphere, develops a relative low in surface pressure, which acts to increase low-level dynamical and moisture convergence into this region. Such low-level convergence forces stronger vertical motion into the region of diabatic heating, with the associated moisture convergence providing a source of water for continued condensation. Diabatic heating increases further in the same region, increasing the dynamical response and a feedback loop develops. Such mechanisms are at the heart of Kuo-type convection schemes (Ooyama 1964; Kuo 1965; Anthes 1977).

Global Environmental Multiscale uses the Kain-Fritsch (KF) convection scheme (Fritsh and Chappell 1980; Kain and Fritsch 1990), employing a CAPE closure to determine the intensity of convective heating. The closure assumes $90 \%$ of the CAPE existing in a vertical column is removed by convection in a specified adjustment period, equal to the time for a convective column to be advected across a model grid box by a wind speed representative of the vertical depth of the convective column in that grid box. This time period is further constrained to lie between a minimum of 30 and a maximum of $60 \mathrm{~min}$. The implication of such a closure is that as model resolution increases the CAPE adjustment period will decrease, so when destabilized (e.g. by atmospheric radiative cooling) the model atmosphere more rapidly adjusts back to neutral conditions (zero CAPE) at higher resolution, with larger convective heat and moisture tendencies, operating over a shorter time period, being the result. The KF scheme also employs a convective trigger function to determine when and where a model grid column supports convective mixing beyond a minimum vertical extent. The KF trigger function compares the buoyancy of a lifted parcel, at its lifting condensation level (LCL), to the surrounding environment, with a temperature (buoyancy) perturbation added to the parcel temperature, calculated as a function of the resolved vertical velocity at the LCL, normalized by the 
inverse of the grid box area (Fritsch and Chappell 1980). If the thermally-augmented parcel is found to be buoyant, convection is allowed in the column. Such an approach recognizes that resolved vertical velocities will likely increase as model resolution increases, aiming to make the triggering of convection resolution independent.

We suggest an increased convective stabilization rate (through the CAPE closure sensitivity) with increasing resolution, acts to make moist unstable regions in the high-resolution GVAR domain more responsive to radiatively-driven destabilization than in the lower resolution simulations. Through the resulting heat and moisture tendencies, convection in climatologically supportive areas of the high-resolution part of the domain grow, through a CISK-like mechanism, more rapidly than similar areas in the low-resolution simulations. This differential response results in a stronger anomalous zonal circulation with anomalous upper-level easterlies and lower-level westerlies over the tropical Atlantic in the high-resolution simulation.

Such a resolution dependent result has important implication for assessing climate change responses, particularly in tropical regions, as the primary forcing term from increasing $\mathrm{CO}_{2}$ is also a vertical stabilization of the tropical atmosphere. In this future climate, the upper-level (mid- to upper troposphere) temperature increase is amplified by the release of latent heat by moist convecting air, resulting in a more stable atmosphere. Although there are some discrepancies between models and observations in regards to this "amplification" over the tropics for the current climate (Karl et al. 2006), it appears to be a robust feature of future climate simulations (Hill and Lackmann 2011). Over the oceans, the magnitude of this amplification is model and scenario dependent, with the largest surface warming linked to the largest increase in mid- to upper tropospheric warming. This is a direct consequence of the moist adiabatic lapse rate decreasing as surface temperatures increase.

For comparison purposes, we show in Fig. 12 the expected change in vertical lapse rate over a 100 year period (2090-2099 vs. 1990-1999) in three different SRES emission scenarios (Nakićenović e al. 2000). The data are taken from table 2 in Hill and Lackmann (2011) and represent a 13-GCM-member ensemble mean, spatially averaged over the western tropical Atlantic $\left(8.5^{\circ} \mathrm{N}, 15^{\circ} \mathrm{N}\right.$, $40^{\circ} \mathrm{W}, 60^{\circ} \mathrm{W}$ ). While the future scenarios all simulate an increase in SSTs, here we emphasize the change (reduction) in the vertical lapse rate, hence Fig. 12 plots the lapse rate changes relative to a surface change normalized to zero, for case of presentation. Figure 12 shows that even the lowest emission scenario (B1) projects a change in temperature profile greater than the one resulting from the modifications introduced here in the radiation scheme. Given the resolution-dependent response observed with

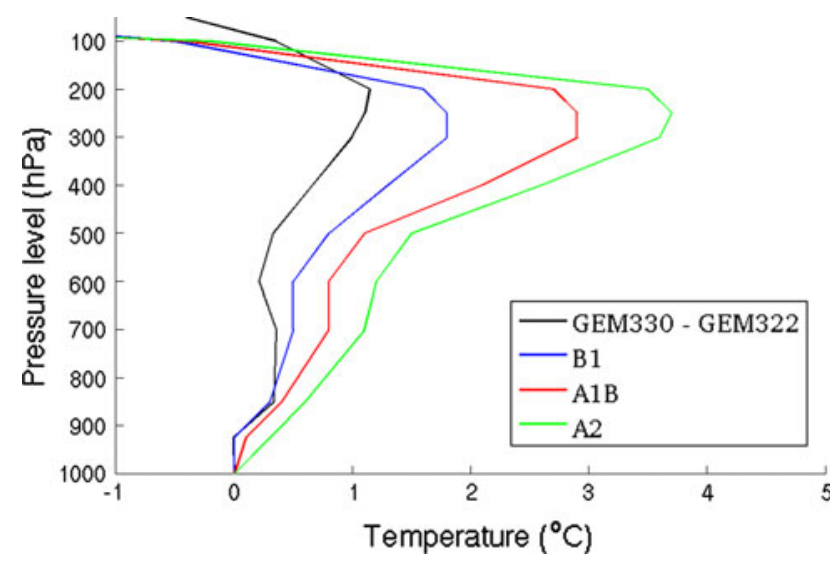

Fig. 12 Spatially averaged difference in vertical lapse rate (normalized to "zero" surface warming) between future climate scenarios (2090-2099) and past (1990-1999) climate over the western Atlantic $\left(8.5^{\circ} \mathrm{N}, 15^{\circ} \mathrm{N}, 40^{\circ} \mathrm{W}, 60^{\circ} \mathrm{W}\right)$ region. Each profile represents a 13-member ensemble-mean. For comparison, we also show the difference in vertical profile (over the entire MDR) between the two GEM versions. The data used to plot the vertical profiles are taken from table 2 in Hill and Lackmann (2011)

GEM, projections of future Atlantic TC activity linked to increased GHGs (either through direct TC statistics or indirectly through cyclogenesis indices) may be highly resolution dependent.

\section{Conclusion}

With an aim to correct a cold bias in tropical tropospheric temperatures in GEM, modifications were introduced to the model radiation scheme, the most significant of which was a reduction in the ice effective radius. In GEM 322, larger ice effective radii lead to reduced absorption of upwelling IR in the UTT. This reduced absorption was accompanied by a positive bias in OLR in tropical convective regions and a cold bias in the mid- to upper troposphere compared to ERA40 and to GEM 330. The basic radiation changes and thermal stability response are the same whether the fixed or variable resolution version of the model are considered. However, the response of convection and impact on the tropical circulation are strongly dependent on the model resolution.

In the variable resolution, the convective scheme in the high resolution region of GVAR responds more readily to the larger instability in GEM 322 (doing so in areas most supportive for convection, e.g. off the African coast) than in other lower, fixed resolution simulations. Thus, in GVAR 322 versus GVAR 330, we see a large increase in convection ( $\omega$ at $700 \mathrm{hPa}$ ) off Africa and in the eastern Pacific. This difference is significantly larger than in simulations performed with a regular grid at $2^{\circ}$, where only a marginal convection response is detected. 
The larger response of convection in supportive regions, such as the east Atlantic and Pacific, impacts the zonal circulation over the Atlantic, leading to reduced shear over the tropical Atlantic in GVAR 322 compared to GVAR 330. This change in vertical wind shear is then seen to be the main driver of changes in TC activity over the basin.

Unlike the GVAR simulations, the lower resolution integrations show a significantly reduced convective response over areas already prone to convection and, consequently, do not reproduce the circulation changes observed in the GVAR integrations. Given that the radiative changes introduced lead to changes in the tropical vertical lapse rate smaller than those expected in the most optimistic SRES scenario, this resolution dependent response of the zonal circulation highlights the importance of accurate representation of cloud and radiation process in models, both for TC prediction on weather and seasonal timescales, and for estimating the response of TCs to increasing concentrations of GHGs.

Acknowledgments The authors would like to thank ECMWF for making the ERA-40 reanalyses available and the National Hurricane Center for the use of their tropical cyclone best track data (HURDAT). This research was supported in part by the Natural Sciences and Engineering Research Council of Canada and the Mathematics of Information Technology and Complex Systems (MITACS, grant number 61851). The first author would also like to thank Katherine Barrett for her help in proofreading this document. Finally, we would like to thank two anonymous reviewers for suggesting improvements to the original manuscript.

Open Access This article is distributed under the terms of the Creative Commons Attribution License which permits any use, distribution, and reproduction in any medium, provided the original author(s) and the source are credited.

\section{References}

Anthes R (1977) A cumulus parameterization scheme utilizing a onedimensional cloud model. Mon Weather Rev 105:270-286

Bélair S, Mailhot J, Strapp JW, MacPherson JI (1999) An examination of local versus nonlocal aspects of a TKE-based boundary layer scheme in clear convective conditions. J Appl Meteorol 38:1499-1518

Bélair S, Crevier L-P, Mailhot J, Bilodeau B, Delage Y (2003) Operational implementation of the ISBA land surface scheme in the Canadian regional weather forecast model. Part I: warm season results. J Hydrometeorol 4:352-370

Bélair S, Mailhot J, Girard C, Vaillancourt P (2005) Boundary layer and shallow cumulus clouds in a medium-range forecast of a large-scale weather system. Mon Weather Rev 133:1938-1959

Betts AK, Harshvardan J (1987) Thermodynamic constraint on the cloud liquid water feedback in climate models. J Geophys Res 92:8483-8485

Boudala FS, Isaac GA, McFarlane NA, Li J (2007) The Sensitivity of the radiation budget in a climate simulation to neglecting the effect of small ice particles. J Clim 20:3527-3541

Bougeault P, Lacarrère P (1989) Parameterization of orographyinduced turbulence in a mesobeta-scale model. Mon Weather Rev 117:1872-1890
Caron L-P, Jones CG (2011) Understanding and simulating the link between African easterly waves and Atlantic tropical cyclones using a regional climate model: the role of domain size and lateral boundary conditions. doi:10.1007/s00382-011-1160-8

Caron L-P, Jones CG, Winger K (2011) Impact of resolution and downscaling technique in simulating recent Atlantic tropical cyclone activity. Clim Dyn 5:869-892. doi:10.1007/s00382010-0846-7

Charney JG, Eliassen A (1964) On the growth of the hurricane depression. J Atmos Sci 21:68-75

Charron M, Polavarapu S, Buehner M, Vaillancourt P, Charette C, Roch M, Morneau J, Garand L, Aparicio JM, Macpherson S, Pellerin S, St. James J, Heilliette S (2011) The stratospheric extension of the Canadian operational deterministic medium range weather forecasting system and its impact on tropospheric forecasts. Mon Weather Rev. doi:10.1175/MWR-D-11-00097

Côté J, Gravel S, Methot A, Patoine A, Roch M, Staniforth A (1998) The operational CMC/MRB Global Environmental Multiscale (GEM) model: part I-design considerations and formulation. Mon Weather Rev 126:1373-1395

Emanuel KA, Nolan D (2004) Tropical cyclone activity and globa climate. In: 26th conference on hurricanes and tropical meteorology. Amecian Meteorological Society, Miami, pp 240-241

Fox-Rabinovitz M, Cote J, Dugas B, Deque M, McGregor JL, Belochiski A (2008) Stretched-grid model intercomparison project: decadal regional climate simulations with enhanced variable and uniform-resolution GCMs. Meteorol Atmos Phys 100:159-177

Fritsch JM, Chappell CF (1980) Numerical prediction of convectively driven mesoscale pressure systems. Part I: convective parameterization. J Atmos Sci 37:1722-1733

Gleckler P (1996) Atmospheric model intercomparison project newsletter. No. 8, PCMDI/LLNL. Available online at http:// www-pcmdi.llnl.gov/projects/amip/NEWS]

Goldenberg SB, Shapiro LJ (1996) Physical mechanism for the association of El Niño and West African rainfall with Atlantic major hurricane activity. J Clim 9:1169-1187

Gray WM (1975) Tropical cyclone genesis. Department of Atmospheric Science Paper, No. 234, Colorado State University, Fort Collins

Hill KA, Lackmann GM (2011) The impact of future climate change on TC intensity and structure: a downscaling approach. J Clim 24:4644-4661

Jung J-H, Arakawa A (2004) The resolution dependence of model physics: illustrations from nonhydrostatic model experiments. J Atmos Sci 61:88-102. doi:10.1175/1520-0469(2004)061<0088: TRDOMP $>2.0 . \mathrm{CO} ; 2$

Kain JS, Fritsch JM (1990) A one-dimensional entraining/detraining plume model and application in convective parameterization. J Atmos Sci 47:2784-2802

Karl TR, Hassol SJ, Miller CD, Murray WL (eds) (2006) Temperature trends in the lower atmosphere: steps for understanding and reconciling differences. A report by the climate change science program and subcommittee on Global Change Research, Washington, DC, $180 \mathrm{pp}$. http://www.climatescience.gov/Library/ sap/sap1-1/finalreport/default.htm

Kuo HL (1965) On formation and intensification of tropical cyclones through latent heat release by cumulus convection. J Atmos Sci 22:40-63

Laprise R (1992) The Euler equations of motion with hydrostatic pressure as independent variable. Mon Weather Rev 120:197-207

Li J, Barker HW (2005) A radiation algorithm with correlated-k distribution. Part I: local thermal equilibrium. J Atmos Sci 62:286-309

Markovic M, Lin H, Winger K (2011) Dynamical seasonal prediction using the Global Environmental Multiscale model with a 
variable resolution modeling approach. Clim Dyn. doi:10.1007/ s00382-011-1202-2

McFarlane NA (1987) The effect of orographically excited gravitywave drag on the circulation of the lower stratosphere and troposphere. J Atmos Sci 44:1175-1800

Nakićenović N, coauthors (eds) (2000) Special report on emissions scenarios. A special report of Working Group III of the Intergovermental Panel on Climate Change, Cambridge University Press, Cambridge

Ooyama K (1964) A dynamical model for the study of tropical cyclone development. Geophys Int 4:187-198

Rockel B, Raschke E, Weyres B (1991) A parameterization of broad band radiative transfer properties of water, ice and mixed clouds. Beitr Phys Atmos 64:1-12

Shen W, Tuleya RE, Ginis I (2000) A sensitivity study of the thermodynamic environment on GFDL model hurricane intensity: implication for global warming. J Clim 13:109-121

Sundqvist H, Berge E, Kristjansson JE (1989) Condensation and cloud parameterization studies with a mesoscale numerical weather prediction model. Mon Weather Rev 117:1641-1657
Walsh KJE, Fiorino M, Landsea CW, McInnes KL (2007) Objectively determined resolution-dependent threshold criteria for the detection of tropical cyclones in climate models and reanalysis. J Clim 20:2307-2314

Williamson DL, Boville BA (1998) A comparison of semi-Lagrangian and Eulerian tropical climate simulations. Mon Weather Rev 126:1001-1012

Zadra A, Roch M, Laroche S, Charron M (2003) The subgrid scale orographic blocking parameterization of the GEM model. Atmos Ocean 41:155-170

Zadra A, Caya D, Côté J, Dugas B, Jones C, Laprise R, Winger K, Caron L-P (2008) The next Canadian regional climate model. Phys Can 64:75-83

Zadra A, Vaillancourt P, Roch M, Leduc A-M, Belair S, Dugas B, McTaggart-Cowan R (2012) Sensitivity of tropical cyclone genesis to deep convection triggering parameters (in preparation) 